Revue internationale de l'économie sociale

Recma

\title{
Agenda de la recherche en économie sociale
}

Numéro 336, avril 2015

URI : https://id.erudit.org/iderudit/1030157ar

DOI : https://doi.org/10.7202/1030157ar

Aller au sommaire du numéro

\section{Éditeur(s)}

Association Recma

ISSN

1626-1682 (imprimé)

2261-2599 (numérique)

Découvrir la revue

Citer ce document

(2015). Agenda de la recherche en économie sociale. Revue internationale de l'économie sociale, (336), 21-21. https://doi.org/10.7202/1030157ar d'utilisation que vous pouvez consulter en ligne.

https://apropos.erudit.org/fr/usagers/politique-dutilisation/ 


\section{AGENDA DE LA RECHERCHE EN ÉCONOMIE SOCIALE}

26-27 mai : Rimouski (Canada). Colloque sur le thème "L'innovation sociale en contexte d'austérité ", organisé par le Centre de recherche sur les innovations sociales (Crises, Canada).

27-29 mai : Reims. $X V^{\text {es }}$ Rencontres du Réseau interuniversitaire d'économie sociale et solidaire (Riuess), sur le thème "La créativité de l'ESS est-elle soluble dans l'entrepreneuriat?».

27-30 mai : Paris. Colloque international de l'Alliance coopérative internationale (ACI), sur le thème "Future of the cooperative model ".

10-12 juin : Paris. Colloque Recherche et Régulation sur le thème "La théorie de la régulation à l'épreuve des crises ".

30 juin-3 juillet: Helsinki (Finlande). $5^{\text {th }}$ Emes International Research Conference on Social Enterprise, «Building a scientific field to foster social enterprise eco-system ».

30 juin-3 juillet : Paris. Biennale internationale de l'éducation, de la formation et des pratiques professionnelles, Cnam, sur le thème "Coopérer?».

15-18 juillet: Lisbonne (Portugal). $5^{\text {th }}$ Ciriec International Research Conference on Social Economy, "The social economy in a globalized world».
10-11 septembre: Paris. XXXV Journées de l'Association d'économie sociale (AES), sur le thème "L'économie sociale face à la crise».

27-30 octobre: Salvador (Brésil). $3^{\text {rd }}$ International Conference on Social and Complementary Currencies, "Social currencies in social and solidarity economies: Innovations in development ».

30 octobre: date limite de l'appel à contributions, numéro spécial de M@n@gement, « Organizing alternatives to capitalism ».

10-11 novembre: Antalya (Turquie). ICAILO International research conference, "Cooperatives and the world of work».

10-13 novembre: Antalya (Turquie). Conférence mondiale de l'ACI, "Towards 2020: What will your co-operative look like?».

11-13 octobre 2016: Québec (Canada). III ${ }^{\text {e }}$ Sommet international des coopératives, organisé par l'ACI et le mouvement Desjardins. 